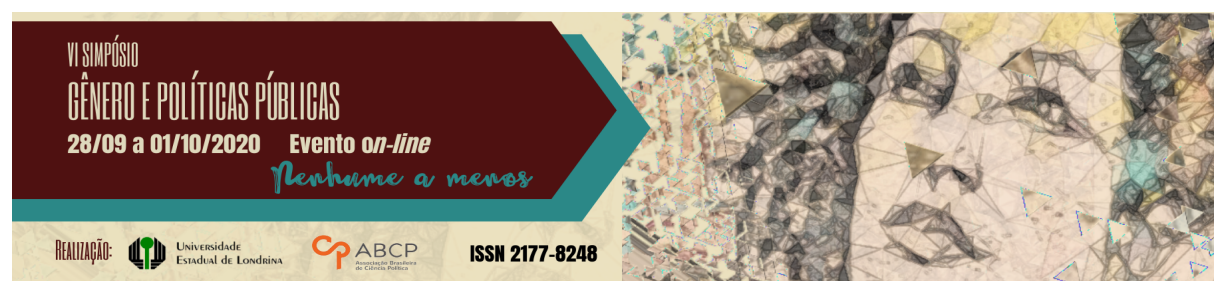

\title{
Limites para a participação das mulheres nos espaços de poder no contexto de avanço do conservadorismo e de vozes antifeministas
}

\author{
Meire Ellen Moreno; ; Lorena Ingred Moreira Pio²
}

\begin{abstract}
Resumo
Diante uma sociedade fortemente marcada pela exclusão das mulheres na esfera política é necessário o esforço para compreender os limites impostos à participação política de mulheres nas decisões do Estado, em especial, na conjuntura atual de avanço do conservadorismo e de vozes antifeministas. Assim, por meio de uma revisão bibliográfica, nosso objetivo é problematizar os limites que a conjuntura política brasileira impõe para a participação das mulheres nas conferências de políticas públicas. Para tanto, apresentaremos parte da crítica feminista ao modelo teórico de democracia deliberativa. A partir da crítica feminista ao deliberativismo, pudemos traçar algumas considerações sobre a participação das mulheres em certos espaços institucionais da política, especificamente, trataremos das Conferências que fizeram parte do processo de formulação do Plano Nacional de Educação 2014 que foi aprovado sem nenhuma referência aos termos gênero e sexualidade/orientação sexual.
\end{abstract}

Palavras-chave: democracia; participação; gênero.

\section{Limits for women's participation in spaces of power in the context of advancing conservatism and anti-feminist voices}

\begin{abstract}
1 Doutoranda do Programa de Pós-graduação em Sociologia da Universidade Estadual de Londrina. Contato: moreno.meire@gmail.com.

2 Mestranda do Programa de Pós-graduação em Sociologia da Universidade Estadual de Londrina. Contato: lorenamoreira1403@gmail.com
\end{abstract}

GT 13 - Gênero, participação e representação política 
In the face of a society strongly marked by the exclusion of women in the political sphere, an effort is needed to understand the limits imposed on the political participation of women in State decisions, especially in the current situation of advancing conservatism and anti-feminist voices. Thus, by means of a bibliographic review, our objective is to problematize the limits that the Brazilian political situation imposes on the participation of women in public policy conferences. To this end, we will present part of the feminist critique to the theoretical model of deliberative democracy. Based on the feminist critique of deliberativism, we were able to outline some considerations about the participation of women in certain institutional spaces of politics, specifically, we will deal with the Conferences that were part of the process of formulating the National Education Plan 2014 that was approved without any reference to the terms gender and sexuality / sexual orientation.

Keywords: democracy; participation; gender.

\section{Introdução}

As desigualdades de gênero e a situação de desvantagem das mulheres em relação aos homens em diversos campos da vida social apresentam-se como temas relevantes ao(s) movimento(s) feminista(s) e aos pensamentos social e político contemporâneos. Um dos problemas importantes e que atualmente requer análise, é o que versa sobre a participação e representação das mulheres nas decisões do Estado. Isso porque as mulheres continuam ocupando uma parcela muito reduzida dos cargos de posição de poder (MIGUEL; QUEIROZ, 2016).

Na tentativa de superação dessa e outras desigualdades, especialmente desde o processo de "redemocratização" da política nacional, movimentos de mulheres e feministas reivindicam o reconhecimento e inclusão de suas demandas nas agendas de governos municipais, estaduais e nacional. Entre outras ações, buscam ampliar a participação e representação feminina nos processos de políticas públicas, entendendo o Estado como espaço estratégico para suas lutas e resistências (FARAH, 2004; MARIANO; GALVÃO, 2014), mesmo diante de limitações impostas por seus valores e desenhos institucionais. 
Cada vez mais as mulheres buscam formas de participação na política através de comissões e conselhos de empresas privadas e órgãos do Estado (YOUNG, 2006, p. 170). No interior da teoria democrática contemporânea, algumas abordagens, entre elas a deliberativa, apostam na centralidade dos espaços de participação, vinculando-os à qualidade da democracia e à legitimidade dos processos de tomada de decisões políticas. Dentre estes espaços de participação, encontram-se as experiências brasileiras das conferências de políticas públicas (FARIA; SILVA; LINS, 2012).

A atuação das mulheres nesses espaços trouxeram conquistas importantes em termos de direitos políticas transversais de gênero no Brasil. No entanto, desde pelo menos o processo eleitoral de 2010, toma corpo e avança discursos conservadores e políticas de extrema direita. No Brasil, o conservadorismo que tem se expressado nas narrativas do anticomunismo, pela influência da perspectiva herdada da "escola econômica austríaca" - marcada pela defesa do neoliberalismo, das liberdades econômicas e individuais, do Estado mínimo e da meritocracia - e do tradicionalismo de gênero (MIGUEL, 2016; MATOS; PINHEIRO, 2012) que se revela na crescente resistência à difusão e a inclusão da agenda feminista nas decisões do Estado.

Grupos que engendram forças contra a agenda feminista nas políticas públicas adotam fortes apelos antifeministas. $\mathrm{O}(\mathrm{s})$ antifeminismo(s) recusa(m) a igualdade entre homens e mulheres e $\operatorname{procura}(\mathrm{m})$ balizar as reivindicações feministas impondo barreiras às possibilidades de ampliação dos direitos das mulheres e outras minorias políticas tais como negros, indígenas, homossexuais etc (CRUZ; DIAS, 2015; FLORES, 2004), prejudicando, ainda mais, a inclusão das vozes feministas nas políticas levadas a cabo pelo Estado.

Nesse sentido, em nosso trabalho importa compreender as questões relacionadas à precária participação das mulheres nas democracias liberais, em particular no que diz respeito às conferências de políticas públicas. Além disso, nos interessa refletir sobre como os impedimentos à participação feminina são reforçados no contexto de 
avanço e fortalecimento de vozes conservadoras, inclusive nos espaços nos quais as mulheres encontram, recentemente, maior espaço para sua atuação política, como é o caso das conferências de políticas públicas.

\section{Qualidade da democracia e os modelos baseados na discussão}

Promover a maior participação política de mulheres, especialmente nos espaços tradicionais de decisão política tais como os órgãos e instituições dos poderes do Estado, não é uma tarefa fácil. Ainda hoje, as mulheres ocupam uma pequena parcela dos cargos públicos eletivos nos sistemas políticos; estão pouco presentes nas posições de poder e exercem pouca influência na vida pública e privada (YOUNG, 2006). Tal situação coloca em xeque as prerrogativas de que as democracias são formas de governos inclusivas em si.

Segundo Avritzer e Santos (2003), apesar das posições otimistas ou pessimistas, a democracia assumiu um lugar central nos estudos políticos no século XX. A partir da segunda metade do último século vivido, o debate sobre a democracia abrangeu dois temas principais: $\mathrm{o}$ primeiro, ocorrido até a metade do século, se concentrava na desiderabilidade ou não da democracia como forma de governo. Após resolvida a questão em favor da democracia, gerou-se um consenso sobre o procedimento eleitoral como forma legítima para a formação dos governos. Entre as consequências, destacamos a restrição das formas de participação e soberania ampliadas.

Com o declínio do Estado de bem estar social e os cortes de políticas sociais a partir da década de 1980, as afirmações sobre os efeitos distributivos irreversíveis da democracia foram desafiados. Além disso, o debate sobre as os limites estruturais do modelo hegemônico democrático liberal votocêntrico realizados, por exemplo, em estudos na América Latina, tornou desatualizadas as perspectivas sobre a democracia. Estava em jogo a compatibilidade ou não entre democracia e capitalismo (AVRITZER; SANTOS, 2003). 
Assim, a partir dos anos de 1990, a discussão que viria dominar os debates passou a se concentrar no problema da forma, variação e qualidade da democracia. A teoria hegemônica da democracia, depois do fim da guerra fria e com o avanço do processo de globalização, encontra um conjunto de perguntas não resolvidas. Estas questões apresentam-se com maior evidência nos países de maior diversidade étnica, entre os grupos com maior dificuldade de terem reconhecidos seus direitos, onde a diversidade de interesses choca-se com o particularismo das elites econômicas (AVRITZER; SANTOS, 2003), como é o caso brasileiro.

Segundo Avritzer e Santos (2003), no período do pós-guerra, teriam surgido concepções alternativas ou contra-hegemônicas sobre a democracia. Tais concepções mantiveram a resposta procedimental ao problema da democracia, porém, entendendo-a como possibilidade de aperfeiçoamento da convivência entre seres humanos. Trata-se, portanto, da negação de formas homogeneizadoras de organização da sociedade em favor do reconhecimento da pluralidade humana.

Entre as abordagens da teoria democrática contemporânea, destacamos as deliberativas que, apesar de suas variações, tem em comum a aposta na centralidade dos espaços de participação, vinculando-os à qualidade da democracia e à legitimidade dos processos de tomada de decisões políticas. Entre as formas alternativas de políticas democráticas para ampliar a participação, se encontram as experiências brasileiras das conferências de políticas públicas (FARIA; SILVA; LINS, 2012).

O modelo democrático baseado na discussão emergiu nas últimas décadas do século XX (HELD, 2006; MOUFFE, 2005; YOUNG, 2001; WALZER, 2007). Embora existam distintas posições entre seus defensores, é possível afirmar que o foco dos modelos democráticos deliberativos é a qualidade da democracia. Os democratas deliberativos defendem um debate informado, o uso público da razão e da imparcialidade para os processos políticos entre cidadãos livres e iguais (HELD, 2006; MOUFFE, 2005), que se concentram nas definições 
e nos procedimentos de formação de preferências e de aprendizagem dentro da política e da sociedade civil (HELD, 2006).

Para os teóricos da democracia deliberativa, é possível alcançar acordos que satisfaçam a racionalidade através de procedimentos adequados à deliberação - entendida como defesa dos direitos liberais - e a legitimidade democrática - vista como soberania popular. Os perigos da soberania popular para os valores liberais podem ser evitados redefinindo-a em termos intersubjetivos, como "poder gerado comunicativamente" (MOUFFE, 2005, p. 12). Para que o processo deliberativo seja possível, é necessária uma multiplicidade de pontos de vista e argumentos. Cada parte defende seus argumentos e procura refutar os argumentos desaprovados até que um consenso entre as partes seja alcançado (MANIN, 2007).

Apesar das diferentes tendências, um dos objetivos da abordagem deliberativa compartilhado por diferentes teóricos é o de assegurar uma ligação forte entre democracia e liberalismo. A autoridade e legitimidade se assentam em certas formas de razão pública, da crença em uma forma de racionalidade que além de instrumental tem sua dimensão normativa. O campo próprio da política é identificado com a troca de argumentos entre pessoas razoáveis guiadas pelo princípio da imparcialidade (MOUFFE, 2005).

A deliberação é, portanto, um momento de discussão no qual as/os participantes da esfera política/pública expõem suas reivindicações e discutem sobre elas. A deliberação é, segundo seus defensores, necessária para a tomada de decisões incertas e a partir dela pode-se chegar à maneira certa de agir (MANIN, 2007). A legitimidade democrática não é a vontade pré-determinada dos indivíduos, mas sim a formação dela durante o processo de deliberação, quando a vontade de cada um é transformada e acrescentada com a vontade de outros indivíduos, e não, a soma das vontades já pré-definidas. 
Outra característica do processo de deliberação, é que ele é simultaneamente coletivo e individual. Individual porque todos os indivíduos chegam com argumentos individuais e pré-formulados. E coletivo porque para que aconteça o processo deliberativo, é indispensável que haja uma diversidade de pontos de vista e argumentos para que ocorram os debates, onde escuta-se e formula-se outros argumentos. O processo deliberativo leva os indivíduos a terem uma reflexão crítica sobre as opiniões e visões que são apresentadas e defendidas. Segundo Bernard Manin (2007), a partir da deliberação são tomadas muitas decisões, que independentes de boas ou ruins, correspondem a vontade geral. De acordo com Cohen (2007), a democracia deliberativa é o ideal da justificação política, já que a deliberação tem como base a argumentação pública e livre entre iguais.

Nesse procedimento os participantes consideram-se mutuamente como iguais; eles visam defender e criticar as instituições e os programas tendo como critério as considerações que os outros têm razões para aceitar, dado o fato do pluralismo razoável e a suposição de que esses outros são razoáveis; e que eles estão dispostos a cooperar de acordo com os resultados dessas discussões, considerando esses resultados como obrigatórios (COHEN, 2007, p. 122).

Resumidamente, a democracia deliberativa, portanto, pode ser definida pelo processo através do qual uma diversidade de opiniões, argumentações, reivindicações são apresentadas. A partir dessa diversidade, segundo seus defensores, ocorre a deliberação pública, posicionando cidadãs/os como livres e iguais, tomando decisões em conjunto. Por isso, a legitimidade das decisões não se dá nas urnas, mas pela deliberação para a tomada de decisões realizadas por indivíduos livres e iguais, num processo racional de discussão (HELD, 2006). 


\section{Limites da democracia deliberativa a partir de uma perspectiva feminista}

Muitas/os teóricas/os defendem que a democracia deliberativa é um modelo mais igualitário ou inclusivo já que as argumentações para as tomadas de decisões são baseadas em procedimentos racionais entre indivíduos livres e iguais. No entanto, o processo de argumentação deliberativa é carregado de um viés cultural de busca pela universalidade e imparcialidade que trazem consequências para os processos democráticos. O modelo deliberativo silencia e exclui minorias políticas que já são prejudicadas pelas desigualdades estruturais tais como o machismo e o racismo.

Concordamos com a afirmação de Iris Marion Young (2001) de que há, ao menos, dois problemas nos modelos democráticos deliberativos. Em relação ao primeiro, ao se reduzir a discussão à argumentação racional, como propõe a maioria dos teóricos deliberativos, tem-se uma tendência ao silenciamento ou desvalorização de pessoas ou grupos. O segundo problema surge da suposição de que os processos de discussão devam ter por objetivo um único bem comum, deixando de observar as especificidades das demandas de pessoas ou grupos.

Ao afirmar que o modelo de democracia deliberativa provém de contextos institucionais, tais como o debate científico, tribunais modernos, etc. - instituições estas que deram origem à revolução burguesa e que se tornaram dominantes (YOUNG, 2001) - identifica o seu caráter elitista e exclusivista. Para a autora, tais instituições são dominadas por sujeitos das classes economicamente dominantes, do sexo masculino e pela diferenciação por raça. Neste sentido, na medida em que as normas que regulam os processos deliberativos são culturalmente específicas, tendem ao silenciamento ou desvalorização de certos discursos.

Geralmente, os debates acontecem em arenas políticas que dificilmente são abertas para o público, tanto no que diz respeito aos 
locais quanto aos horários preferidos para sua realização. Assim, é necessário dispor de tempo para participar. Neste aspecto, as mulheres enfrentam muitas dificuldades e acabam sendo prejudicadas diante às exigências sociais de sua participação em vários locais de trabalho cuidando das/os filhas/os e trabalhando "fora", por exemplo. Assim, a "medida em que as desigualdades estruturais na sociedade operam de forma eficaz para restringir o acesso [como no caso das mulheres] a esses processos deliberativos, suas deliberações e conclusões não são legítimas" (YOUNG, 2014, p. 1991).

Apesar de suas tendências elitistas, defensores da democracia deliberativa afirmam que ela pode ser mais inclusiva e igualitária; tendem a afirmar que, para se atingir igualdade entre as partes em discussão, basta o isolamento do poder político e econômico. Não consideram em suas discussões a desvalorização de determinados discursos e a elevação de outros já que supõem que a deliberação é neutra e universal em relação à cultura (YOUNG, 2001).

No processo de deliberação - baseado no ideal de neutralidade e imparcialidade - diferenças de raça, gênero e sexualidade, tendem a não ser consideradas. As discussões e as argumentações deliberativas não possibilitam o adequado reconhecimento das reivindicações de todas e todos, mas sim, uma competição na qual os participantes têm a intenção de vencer os debates e não alcançar um entendimento mútuo acerca de um tema (YOUNG, 2001).

Em tal modelo, são privilegiados aqueles/as que têm mais experiência na arena política, que dispõem de maior conhecimento do discurso e do convencimento político e melhor conhece as regras do jogo. Geralmente, homens cis, ricos, brancos e heterossexuais são os participantes privilegiados da arena política/pública, ocorrendo o silenciamento e desvalorização das vozes das minorias políticas, tais como as mulheres.

São frequentes as críticas feministas contra o paradigma racional moral defendido nos discursos de justiça e direitos, 
supostamente baseados na neutralidade e imparcialidade, presentes nos argumentos dos teóricos deliberativos. Segundo Young (2012), as críticas feministas às teorias políticas enfatizam que tal ideal reforça distinções excludentes. Young (2014), por exemplo, nos apresenta três maneiras de como o ideal de imparcialidade nega e reprime as diferenças: ao negar a particularidade das situações e das realidades individuais; na medida em que a exigência de suspensão das paixões, a imparcialidade procura dominar ou eliminar a heterogeneidade das formas de sentimentos; e porque o ideal da imparcialidade reduz a particularidade à unidade e a pluralidade dos sujeitos morais a questões de subjetividade.

As mulheres ocupam uma pequena parcela dos cargos públicos eletivos nos sistemas políticos, e estão pouco presentes nas posições de poder, exercendo pouca influência na vida pública e privada de modo geral. Por essa e outras razões, cada vez mais, os movimentos feministas buscam formas alternativas às legislaturas com o objetivo de intervir nas políticas de Estado e governo (YOUNG, 2006).

Diversas propostas que têm por objetivo a inclusão política de grupos minoritários defendem a adoção de medidas que proporcionem maior representação dos grupos sub-representados. Entre elas, destacamos que a participação por meio de comissões, conferências e conselhos de empresas privadas e órgãos do Estado tem se tornado uma estratégia do movimento feminista (YOUNG, 2006) e das mulheres de forma geral. Apostando na centralidade dos espaços de participação, vinculando-os à qualidade da democracia e à legitimidade dos processos de tomada de decisões políticas, feministas brasileiras têm dirigido esforços na atuação nas conferências (FARIA; SILVA; LINS, 2012) e conselhos gestores de políticas públicas, mesmo diante os limites que à elas se apresentam para sua participação.

Tal como afirmam Faria, Silva e Lins (2012, p.249), entendemos as conferências de políticas públicas "como espaços institucionais de participação e deliberação acerca das diretrizes gerais de uma determinada política pública, podendo assumir um caráter consultivo 
ou deliberativo". Tais espaços refletem os esforços de mobilização social e de diálogo para influenciar a definição de uma política pública, mas também refletem as desigualdades da sociedade em geral.

No Brasil, as "conferências nacionais tornaram-se importantes processos na ampliação da participação social” (AVRITZER, 2012, p. 7). Desde a realização da Conferência de Saúde convocada pelo governo Getúlio Vargas em 1937, tem se adotado a prática de conferências nacionais (AVRITZER, 2012; FARIA; SILVA; LINS, 2012) e a previsão na Constituição Federal de 1988 para formas de participação da sociedade civil na construção e avaliação de políticas balizou um processo de sua institucionalização (MORENO, 2016).

\section{Participação das mulheres em contexto de avanço de vozes conservadoras e antifeministas}

No final do século XX a democracia parecia ser a única forma legítima de governo. No entanto, não há razões para acreditar na força desse suposto consenso. Por um lado, poucos ousam desafiar o modelo liberal-democrático, por outro, os sinais de desapreço pelas instituições estão se tornando generalizados. Cada vez mais, percebe-se, por exemplo, a insatisfação das pessoas em relação aos partidos políticos que não conseguem mais atender seus interesses e o crescimento dos partidos de extrema-direita na Europa (MOUFFE, 2005) e também na América Latina e Brasil. Os fundamentos e instituições democráticas estão sob ameaça e compreender os limites institucionais para a inclusão política das mulheres parece-nos fundamental.

Além disso, quando falamos sobre participação das mulheres na política, vale lembrar que até recentemente, a filosofia política dominante aceitava a discriminação sexual e seus modos sutis de operação. Até boa parte do século XX, era recorrente entre teóricos a ideia de uma suposta "natureza" feminina enclausurava as mulheres à esfera da família e à sujeição aos seus maridos. Para muitas feministas, os princípios e as instituições desenvolvidos a partir das experiências e 
interesses masculinos não possibilitam o adequado reconhecimento das necessidades das mulheres, tampouco incorporaram suas experiências nas agendas de Estado e governo.

$\mathrm{Na}$ contemporaneidade, pouco a pouco, as suposições de inferioridade natural das mulheres foram abandonadas pelos teóricos (KYMLICKA, 2006), no entanto, garantir a participação equânime, em termos de gênero, nas decisões do Estado, ainda é um desafio a ser enfrentado, especialmente num contexto de ameaças às instituições democráticas e de avanços de vozes antifeministas, num país sob um governo conservador, como é o nosso caso.

No Brasil, desde pelo menos o processo eleitoral de 2010, cresce e toma corpo a influência de vozes conservadoras no cenário político (MIGUEL, 2016), sobretudo o tradicionalismo de gênero (MATOS; PINHEIRO, 2012) que se revela na insistente resistência à difusão e a inclusão da agenda feminista na formulação de políticas públicas e nas ações do Estado. Grupos que engendram forças contra a agenda feminista nas políticas públicas adotam fortes apelos antifeministas. Como uma reação organizada às lutas e conquistas do(s) movimento(s) feminista(s), recusam a igualdade entre homens e mulheres e procuram balizar as reivindicações feministas ao impor ainda mais barreiras às possibilidades de ampliação dos direitos das mulheres (CRUZ; DIAS, 2015; FLORES, 2004):

Há os movimentos antifeministas que procuram restringir os direitos das mulheres, como é o caso das militantes contra o aborto ou contra a prostituição. Também é o caso dos grupos que defendem que as mulheres têm o direito de votar, mas que não devem se candidatar porque o seu papel na sociedade é ser mãe e rainha do lar - e qualquer atuação política significaria a negação de sua feminilidade (CRUZ; DIAS, 2015, p. 40).

Entre tantos aspectos conjunturais que colaboram para a compreensão desse fenômeno e que favorecerem a organização social e política das direitas brasileiras, destaca-se o relevo que tomou a 
influência de setores das igrejas evangélicas e católica como novas articuladoras da sociabilidade. Em grande medida, são aliadas na disseminação dos valores capitalistas, da meritocracia e antifeministas e ameaçam as bases democráticas e os direitos fundamentais de grupos subalternos.

Em relação ao(s) movimento(s) feminista(s), desde pelo menos a IV Conferência Mundial sobre as Mulheres, realizada em Pequim em 1995 e considerada a maior e mais importante das conferências sobre as mulheres e que promoveu avanços conceituais e programáticos, principalmente em relação à inclusão da perspectiva de gênero e da agenda feminista nas agendas governamentais, grupos conservadores reagem à organização e resultados alcançados pelas lutas organizadas das mulheres (MORENO, 2016). Sob o rótulo do combate à chamada "ideologia de gênero", grupos conservadores antifeministas engendram forças contrárias à incorporação desta perspectiva nas políticas públicas, provocando efeitos significativos na formulação e definição dos documentos orientadores de políticas.

Em particular, os documentos orientadores de políticas educacionais têm sofrido alterações relevantes e têm sido campo de disputas no cenário atual de resistência à inclusão da agenda de gênero nas políticas de Estado. Um caso emblemático é o processo político do Plano Nacional de Educação de 2014. O PNE é um importante documento que estabelece metas e estratégias para a educação nacional em todos os seus níveis e deve ser considerado como uma política de Estado e não de governos.

No processo de sua elaboração tomou forma uma disputa política travada em torno da construção do texto do PNE 2014 que caracteriza o cenário atual de resistências e oposições à agenda feminista na política brasileira atual que se intensificou após a eleição de Jair Messias Bolsonaro com a retomada da tramitação dos projetos do "Escola sem Partido" que defende uma suposta neutralidade nos processos pedagógicos e de construção do conhecimento. 
Entre as muitas polêmicas envolveram seu processo de formulação, destacamos a não inclusão da diretriz que versava sobre a promoção da igualdade de gênero apresentada como emenda ao texto original do Poder Executivo. Críticos fundamentam seus argumentos na afirmação de que o uso dos termos gênero e sexualidade introduziram, nas políticas educacionais, a chamada "ideologia de gênero". Tal ideologia traria efeitos na produção e disseminação de materiais didáticos e outros recursos, e incentivaria a homossexualidade e promoveria o fim da família tradicional.

No processo político de formulação do PNE 2014, ocorreram avanços importantes nas discussões sobre políticas educacionais com perspectiva de gênero nos momentos em que se deu a participação da sociedade civil e dos movimentos sociais. Por outro lado, os principais momentos de inflexão aconteceram nas instâncias institucionais e tradicionais do poder político. O PNE/2014 foi aprovado pelo Congresso Nacional e sancionado pelo poder executivo sem nenhuma referência aos termos de gênero e sexualidade em seu texto final.

Consideramos que a não inclusão dos termos gênero e orientação sexual/sexualidade no Plano oculta as desigualdades que operam na e pelas políticas educacionais e que elas terão implicações negativas para a educação e vidas das meninas e mulheres de nosso país. Neste sentido, apesar das movimentações recentes tanto por parte das feministas quanto pelo governo para ampliar a participação e a representação das mulheres nos espaços tradicionais de decisões políticas, o cenário atual é pouco favorável para a definição de políticas mais inclusivas quanto às demandas das mulheres, o que tem consequências para a manutenção de direitos e inclusão da agenda de gênero nas políticas públicas em nosso país.

É válido destacar que, neste contexto, com o fortalecimento das políticas econômicas levadas a cabo por grupos da direita, os Estados passaram a reduzir as políticas redistributivas e a transferir para a sociedade a responsabilidade do atendimento das demandas sociais. As consequências de tal ofensiva na vida econômica e política das 
mulheres reforçam as dificuldades tradicionalmente enfrentadas para a inclusão de suas demandas nas decisões do Estado. A carência de serviços públicos tais como creches e atendimento à saúde integral somadas ao desemprego ou precariedade do trabalho colocam limites à autonomia e participação das mulheres nos espaços de poder.

Compreender a participação das mulheres nos espaços de decisão políticas requer o entendimento de que a legitimidade democrática vincula-se à participação substantiva dos potencialmente atingidos. Tal participação não se limita a mera discussão entre argumentos racionais, mas na inclusão de um amplo conjunto de vozes dissonantes permitindo a presença dos diferentes nestes âmbitos. É preciso ter em mente que além de arranjos institucionais mais inclusivos, é necessário que as os grupos minoritários, tais como as mulheres, tenham condições econômicas e de disponibilidade de tempo entre outros recursos necessários à participação nos espaços de decisão políticas tais como as conferências de políticas públicas.

\section{Considerações finais}

A precária participação e representação das mulheres em relação aos homens na política do Estado não é resultante do desinteresse "natural" por parte das mulheres ou apenas de um veto de gênero por parte dos partidos e organizações de lutas políticas em geral. Existem barreiras sociais, culturais e políticas, que são historicamente construídas, e que são reforçadas pelas vozes e políticas conservadoras e antifeministas, tornando ainda mais difíceis as possibilidades de participação feminina nos processos de políticas públicas.

Em nosso entendimento, na atual conjuntura, os limites impostos para a participação e representação das mulheres e da inclusão da agenda de gênero nas políticas públicas são reforçadas pelas políticas neoliberais e pelo avanço dos discursos conservadores. 
As tradicionais barreiras institucionais para a participação das mulheres nas decisões do Estado tomam novos contornos.

Além disso, destacamos que se até 2010 os espaços de deliberação das conferências de políticas públicas foi entendido como privilegiado para a participação das mulheres e para a incorporação da agenda de gênero nas políticas levadas a cabo pelo Estado, recentemente os encaminhamentos resultantes das discussões realizadas nesses espaços não encontram a observância do Estado. Além das decisões da sociedade civil serem descartadas pelos governos, há a preocupação de que as vozes conservadoras ocupem também esses espaços.

O fato das mulheres ocuparem uma pequena minoria das cadeiras legislativas e nos cargos de chefia do poder executivo no Brasil, por si só, não explica tais fenômenos. A presença cada vez maior de vozes e práticas conservadoras na política brasileira se apresenta como um fator relevante para os retrocessos atuais em termos de políticas públicas com perspectiva de gênero no Brasil e como uma barreira atual para a participação feminina nas decisões do Estado.

Concluímos que o cenário atual é pouco favorável para participação política das mulheres, mesmo nos espaços que se pretendem mais inclusivos e tal situação provoca consequências para a manutenção de direitos e inclusão da agenda de gênero nas políticas públicas em nosso país.

\section{Referências}

AVRITZER, Leonardo; SANTOS, B. de Souza. Introdução: para ampliar o cânone democrático. In: Democratizar a democracia: os caminhos da democracia participativa. 2. ed. Rio de Janeiro: Civilização Brasileira, 2003. p. 39-82. 
COHEN, Joshua. Procedimento e substância na democracia deliberativa. In: WERLE, D. e MELO, Rúrion S. (orgs.). Democracia deliberativa. São Paulo: Esfera Pública, 2007. p. 115-144.

CRUZ, Maria H. S.; DIAS, Alfrancio F. Antifeminismo. Revista de Estudos de Cultura, n. 1, p. 33-42, jan./abr. 2015.

FARAH, Marta Ferreira Santos. Gênero e políticas públicas. Revista Estudos Feministas, Florianópolis, v. 12, n. 1, p. 47-71, 2004.

FARIA, Claudia Feres; SILVA, Viviane Petinelli; LINS, Isabella Lourenço. Conferências de políticas públicas: um sistema integrado de participação e deliberação? Revista Brasileira de Ciência Política, n. 07, Brasília, p. 249-284, jan./abr. 2012.

FLORES, Maria Bernardete Ramos. O pensamento antifeminista: a querela dos sexos. História Revista, v. 9, n. 2, p. 227-252, jul./dez. 2004.

HELD, D. Deliberative democracy and the defence of the public realm. In: HELD, D. Models of democracy. 3. Stanford University Press, 2006.

KYMLICKA, Will. Filosofia politica contemporânea. São Paulo; Martins Fontes, 2006.

MANIN, Bernard. Legitimidade e deliberação política. In: WERLE, D.; MELO, Rúrion S. (Org.). Democracia deliberativa. São Paulo: Esfera Pública, 2007.

MARIANO, Silvana A; GALVÃO, Elaine, F. Políticas públicas e perspectiva de gênero: uma abordagem feminista. In: MARIANO, Silvana A. GALVÃO; Elaine, F; CARLOTTO, Cássia M. (Org.). Gestão de políticas públicas com perspectiva de gênero: uma experiência de formação de gestores/as locais. Londrina: 2014. p. 73-87.

MATOS, Marlise; PINHEIRO, Marina Brito. Dilemas do conservadorismo político e do tradicionalismo de gênero no processo eleitoral de 2010: o eleitorado brasileiro e suas percepções. ALVES, José Eustáquio Diniz; PINTO, Céli Regina Jardim; JORDÃO, Fátima (Org.). Mulheres nas eleições 2010. São Paulo: ABCP/Secretaria de Politicas para as Mulheres, 2012.

MIGUEL, Luís Felipe. Da “doutrinação marxista" à "ideologia de gênero" - Escola Sem Partido e as leis da mordaça no parlamento 
brasileiro. Direito e Práxis. Rio de Janeiro, v. 07, n. 15, p. 590-621, 2016.

MIGUEL, Luis F.; QUEIROZ, Cristina M. Diferenças regionais e o êxito relativo de mulheres em eleições municipais no Brasil. Estudos Feministas, Florianópolis, v. 14, n. 2, 2006.

MOUFFE, Chantal. Por um modelo agonístico de democracia. Revista Sociologia Política, Curitiba, n. 25, p. 11-23, nov. 2005

MORENO, Meire Ellen. Feminismos e antifeminismos na política brasileira: "ideologia de gênero e o Plano Nacional de Educação 2014. 2016. Dissertação (Mestrado em Ciências Sociais) - Universidade Estadual de Londrina, Londrina, 2016.

YOUNG, Iris Marion. Comunicação e o outro: além da democracia deliberativa. In: SOUZA, Jessé (Org.). Democracia hoje - Novos desafios para a teoria democrática contemporânea. Brasília: UnB, 2001.

YOUNG, Iris Marion. Representação política, identidade e minorias. Lua Nova, São Paulo, n. 67, p. 139-190, 2006.

YOUNG, Iris Marion. A imparcialidade e o Público Cívico: algumas implicações das críticas feministas da teoria moral e política. In: BENHABIB Seyla; CORNELL Drucilla (Org.). Feminismo como crítica da modernidade: releitura dos pensadores contemporâneos do ponto de vista da mulher. Rio de Janeiro: Rosa dos Tempos, 2012. p. 66-86.

YOUNG, Iris Marion. Desafio ativista à democracia deliberativa. Revista Brasileira de Ciência Política, Brasília, n. 13, p. 187-212, 2014.

WALZER, Michael. Deliberação, e o que mais? In: WERLE, D.; MELO, R. S. (Org.). Democracia deliberativa. São Paulo: Esfera Pública, 2007. p. 299-312. 